\title{
Effect of Chewing Gum on Pain Following Orthodontic Elastomeric Separators Placement: A Randomized Controlled Trial
}

\author{
Ahmed I. Abdul-Aziz*(i) \\ Department of Orthodontics and Dentofacial Orthopedics, Faculty of Dentistry, Assiut University, Assiut, Egypt
}

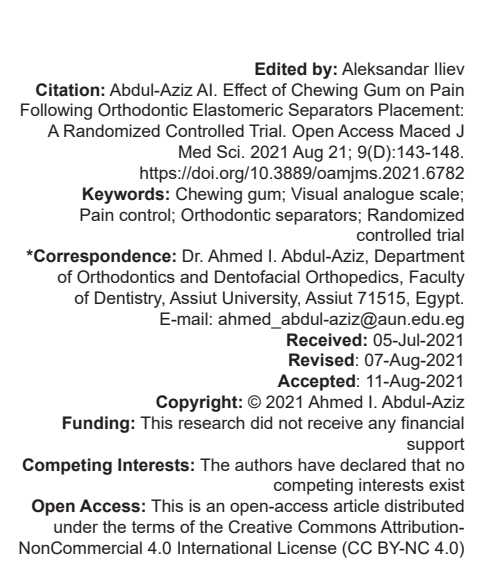

\section{Introduction}

Roughly, $90-95 \%$ of patients feel some degree of pain during orthodontic treatment [1], [2], [3]. Pain and discomfort associated with the placement of the orthodontic separators have unfavorable influence on patient daily activities, eating, and sleep to the degree that pain can be the reason for the patient to discontinue treatment [4], [5], [6], [7]. Orthodontic pain control is vital to raise patients' compliance and cooperation during the whole treatment duration [8].

Systemic analgesics including NonSteroidal Anti-inflammatory Drugs have been the most common investigated strategy to control pain in orthodontic practice [9]. However, this modality of controlling orthodontic pain may be associated with some side effects including gastrointestinal disorders, thrombocytopenia, skin rashes, headaches, allergic reactions, increased blood pressure, reduction in the rate of tooth movement due to inhibition of prostaglandin synthesis [10], [11], [12], [13]. Consequently, it is preferable to use a nondrug substitute that has no adverse effects [14].

It was suggested in Proffit's textbook that orthodontic pain might be minimized by chewing gum
(CG) [15]. CG can control pain by restoring the normal blood flow in the closely tightened periodontal ligaments by loosening them. The restoration of normal blood flow prevents the accumulation of metabolites that triggers pain receptors [16]. In addition, CG renovates lymphatic circulation, thus prevents inflammation and edema and relieves pain and discomfort [17], [18]. Furthermore, CG reduces the incidence of demineralization and caries by stimulation of salivary flow which results in increased bicarbonate concentration and hence the $\mathrm{pH}$ and buffering capacity of saliva; also, it increases the rate of oral sugar and plaque acid clearance [18]

The aim of this randomized controlled trial (RCT) was to investigate whether CG can reduce pain as compared to controls after orthodontic elastomeric separators placement.

\section{Materials and Methods}

\section{Subjects}

The ethical approval of this RCT was obtained from the Institutional Review Board (IRB) of Faculty of 
Medicine, Assiut University, Assiut, Egypt. The study was conducted in a private orthodontic clinic. A detailed explanation of the study steps was given to the patients. They were allowed 1 week to consider whether to participate in this study. If they agreed to take part, an informed consent was signed. Every effort was done in this RCT to ensure the anonymity of the included patients and confidentiality and privacy of information and data. The patients had to meet the following inclusion criteria to be included: medically free and not taking any analgesic therapy, no history of previous orthodontic treatment, with an age range from 20 to 24 years, no obvious cause of pain from odontogenic origin, healthy gingival and periodontal tissues, tight interproximal contacts where the separators were going to be placed, and without temporomandibular joint (TMJ) disorders, especially in the CG group. Pregnant women, patients with cleft lip and palate, syndromes, mental problems, smokers, and phenylketonuria patients, who cannot consume phenylalanine contained in synthetic sugars, were excluded from the study.

\section{Study groups, sample size calculation, randomization, and blinding}

Considering an attrition rate of $25 \%$, a total of 60 patients will be needed for a study with a power of $80 \%$ and an alpha value of 0.05 assuming a large effect size based on previous studies [14], [15], [16]. The randomization was done by a statistician to achieve two equal groups with an allocation ratio of 1:1 using a spreadsheet (Microsoft Excel, Microsoft Office 2016, Microsoft, Redmond, Wash). The allocations were concealed by the dental assistant using consecutively numbered, opaque, and sealed envelopes that were opened only if the patients agreed to join the study and consented. Although blinding of the patients and the operator was not possible because the patients were asked to chew gum or not, the data analyst was blinded to the collected pain scores. Sixty patients were equally randomized to the CG group and non-CG (NG) group with a mean age of $21.82 \pm 0.87$ and $22.31 \pm 1.09$, respectively.

\section{Methods}

Elastomeric separators (Ortho Organizers, Carlsbad, CA, USA) were placed using a plier (American Orthodontics, Sheboygan, WI, USA) in the maxillary arch at the mesial and distal contacts of the first molars on the left and right sides. The patients in the CG group chewed sugar-free gum (Trident, Kent Gida Maddeleri Sanayii ve Ticaret Anonim Sirketi, Cumhuriyet Mah. 2253. Sok. No:11 41400 Gebze, Kocaeli, Turkey) for $10 \mathrm{~min}$ immediately after separators placement and then at 8-h intervals for 1 week, while the patients in the NG group were instructed not to chew any type of gum for the duration of the study. The patients in the two groups were requested not to take any type of analgesics during the week period of the study and to indicate whether they had taken any analgesics.

\section{Data collection}

A $10-\mathrm{cm}$ horizontal line visual analog scale (VAS) was given to the patients which was numbered from zero to 10 with zero indicating no pain, five indicating moderate, and 10 indicating unbearable pain. The patients were asked to register their pain level by writing in the appropriate box the number corresponding to the degree of the pain experienced at $2 \mathrm{~h}, 6 \mathrm{~h}$, bedtime on the same day of separators placement, $24 \mathrm{~h}$, and then daily at 9:00 PM for 1 week after placement of the elastomeric separators. The VASs were collected, and the data were extracted in a spreadsheet.

\section{Statistical analysis}

Statistical Package for the Social Sciences software was used to perform all statistical tests (SPSS, Windows version 26, SPSS Inc., Chicago, Illinois, USA) with a significance level set at $p<0.05$. The pain scores were expressed as mean (SD) and median (min, max). The difference in gender variable was assessed using Chi-square test; while for the age variable, the independent t-test was used. As the Shapiro-Wilk test confirmed the non-normal distribution of pain scores, Mann-Whitney test was used to test for the difference between the two groups at the different time points.

\section{Results}

The baseline characteristics of the two groups are shown in Table 1. There was no significant difference between the two groups with regards to the age and gender variables. None of the patients were lost to follow-up nor discontinued treatment. Three patients (two from NG group and one from the CG group) took analgesics and four patients (one from the NG group and three from the CG group) did not return the VAS, so they were excluded from the analysis. The flow of patients in this RCT is shown in Figure 1. With regards

Table 1: Baseline characteristics of the included patients in the two groups

\begin{tabular}{llll}
\hline & NG $(\mathrm{n}=27)$ & CG $(\mathrm{n}=26)$ & p value \\
\hline Age (years) & $20.1-24$ & $20.1-23.8$ & \\
$\quad$ Range & $22.31 \pm 1.09$ & $21.82 \pm 0.87$ & 0.081 \\
Mean \pm SD & & & \\
Gender & $15(55.6 \%)$ & $9(34.6 \%)$ & 0.126 \\
$\quad$ Male & $12(44.4 \%)$ & $17(65.4 \%)$ & \\
$\quad$ Female & & &
\end{tabular}




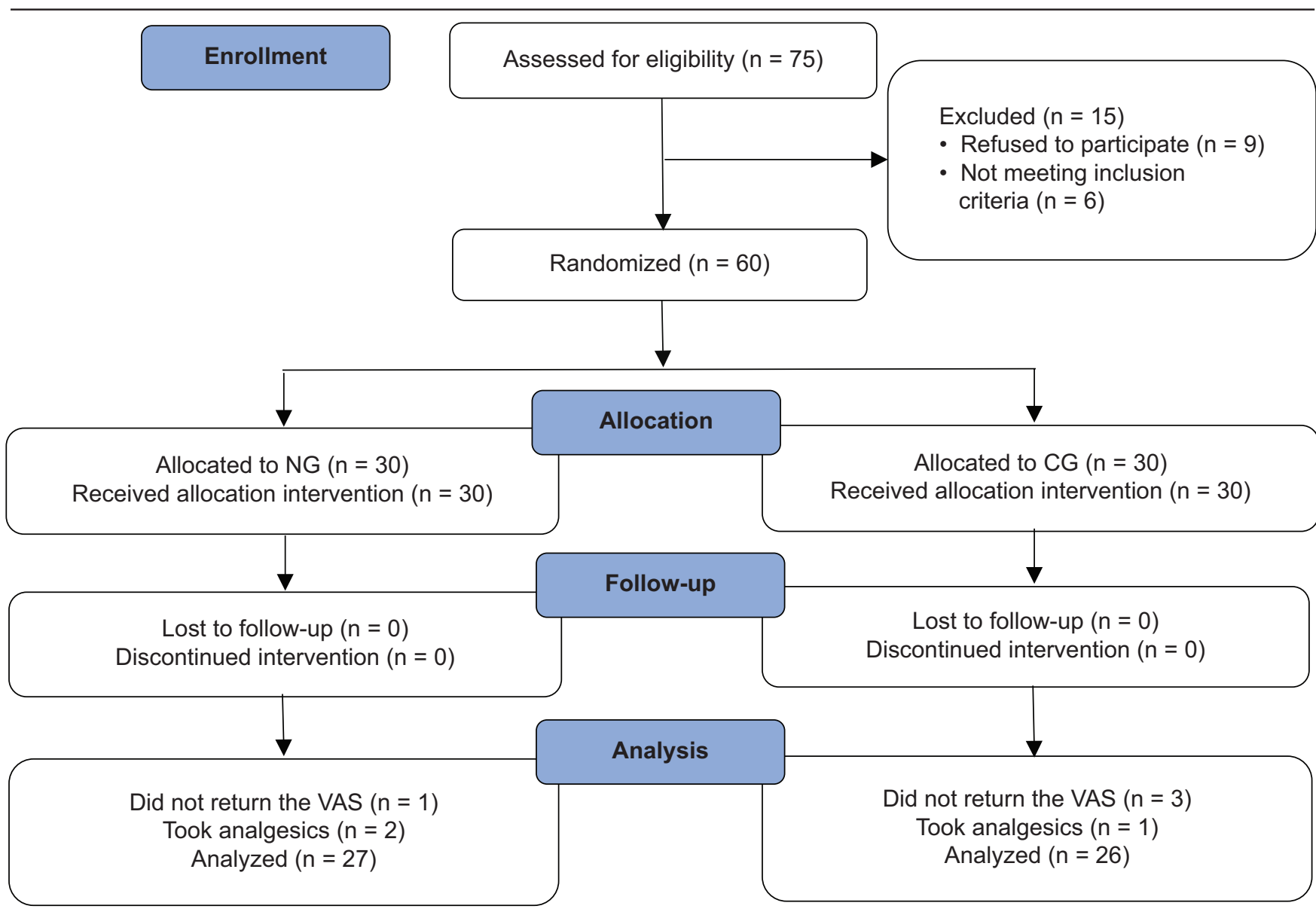

Figure 1: Consolidated Standards of Reporting Trials (CONSORT) flow diagram of the patients through the trial

to the pain scores, they were significantly lower in CG as compared to NG at $2 \mathrm{~h}, 6 \mathrm{~h}$, bedtime, $24 \mathrm{~h}$, and 2 days after separators placement (Table 2). From day 3 to the end of the week duration of the study, the pain scores stayed lower in CG, but the statistical difference was not significant (Table 2). The mean pain scores reached its peak at bedtime in NG and after $24 \mathrm{~h}$ in CG; then, they decreased gradually to its lowest values on day 7 in the two groups (Table 2).

Table 2: Pain scores at different time points in chewing gum (CG) group and non-chewing gum (NG) group

\begin{tabular}{|c|c|c|c|}
\hline Time & $\begin{array}{l}\text { Non-chewing gum (NG) } \\
(\mathrm{n}=27) \\
\text { Mean } \pm \text { SD } \\
\text { Median (min, max) }\end{array}$ & $\begin{array}{l}\text { Chewing gum }(C G)(n=26) \\
\text { Mean } \pm \text { SD } \\
\text { Median (min, max) }\end{array}$ & p value $e^{*}$ \\
\hline $2 \mathrm{~h}$ & $\begin{array}{l}3.33 \pm 1.27 \\
3.00(1.00,6.00)\end{array}$ & $\begin{array}{l}2.12 \pm 0.91 \\
2.00(1.00,4.00)\end{array}$ & 0.000 \\
\hline $6 \mathrm{~h}$ & $\begin{array}{l}4.56 \pm 1.09 \\
4.00(3.00,6.00)\end{array}$ & $\begin{array}{l}3.35 \pm 0.85 \\
3.00(2.00,5.00)\end{array}$ & 0.000 \\
\hline At bedtime & $\begin{array}{l}5.85 \pm 1.10 \\
6.00(4.00,8.00)\end{array}$ & $\begin{array}{l}3.96 \pm 0.72 \\
4.00(3.00,5.00)\end{array}$ & 0.000 \\
\hline $24 \mathrm{~h}$ & $\begin{array}{l}5.52 \pm 0.85 \\
5.00(4.00,7.00)\end{array}$ & $\begin{array}{l}4.35 \pm 0.75 \\
4.00(3.00,6.00)\end{array}$ & 0.000 \\
\hline Day-2 & $\begin{array}{l}4.33 \pm 0.83 \\
4.00(3.00,6.00)\end{array}$ & $\begin{array}{l}3.77 \pm 0.77 \\
4.00(2.00,5.00)\end{array}$ & 0.016 \\
\hline Day-3 & $\begin{array}{l}3.22 \pm 0.80 \\
3.00(2.00,5.00)\end{array}$ & $\begin{array}{l}2.85 \pm 0.73 \\
3.00(2.00,4.00)\end{array}$ & 0.090 \\
\hline Day-4 & $\begin{array}{l}2.78 \pm 0.80 \\
3.00(2.00,4.00)\end{array}$ & $\begin{array}{l}2.31 \pm 0.74 \\
2.00(1.00,3.00)\end{array}$ & 0.075 \\
\hline Day-5 & $\begin{array}{l}1.93 \pm 0.87 \\
2.00(1.00,4.00)\end{array}$ & $\begin{array}{l}1.81 \pm 0.63 \\
2.00(1.00,3.00)\end{array}$ & 0.743 \\
\hline Day-6 & $\begin{array}{l}1.26 \pm 0.81 \\
1.00(0.00,3.00)\end{array}$ & $\begin{array}{l}1.19 \pm 0.75 \\
1.00(0.00,2.00)\end{array}$ & 0.804 \\
\hline Day-7 & $\begin{array}{l}0.78 \pm 0.75 \\
1.00(0.00,2.00)\end{array}$ & $\begin{array}{l}0.65 \pm 0.56 \\
1.00(0.00,2.00)\end{array}$ & 0.637 \\
\hline
\end{tabular}

\section{Discussion}

In this study, we were interested in the difference between the CG and NG groups rather than the change with time within each group. The results of this study showed that the pain scores were lower in the CG group at all time points as compared to the NG group. Although the difference between the two groups was statistically significant at $2 \mathrm{~h}, 6 \mathrm{~h}$, bedtime, $24 \mathrm{~h}$, and 2 days after separators placement; it was non-statistically significant for the remaining of the week duration of the outcome assessment.

Although our results were consistent with Benson et al. [19], Delavarian et al. [20], and Elvina et al. [21] who investigated the effect of CG on orthodontic pain as compared to placebo or no intervention, there were differences between these studies and this RCT.

In Benson et al. study [19], the patients were asked to chew gum whenever required with no standardization to the duration of chewing and to chew gum for $10 \mathrm{~min}$ before filling in the questions at $24 \mathrm{~h}$ and 1 week after placement of the orthodontic appliance. In addition, the patients were allowed to use analgesics and to report whether they took analgesics or not. The age range was different from our study. Furthermore, pain was assessed during the fixed appliance stage not during the separators stage and the treatment 
included both one- and two-arch treatments. Regarding Delavarian et al. [20], the age range was different, and the pain was assessed during the fixed appliance stage while performing four oral functions including chewing, biting, occluding the anterior teeth, and occluding the posterior teeth. For Elvina et al. [21], the age range was different, the sample size was limited with only 10 patients in each group, the patient chewed gum after $2 \mathrm{~h}$ not immediately after separators placement, and the pain was investigated during the fixed appliance stage.

On the other hand, the results of this RCT were not compatible with Otasevic et al. [22], Al-Melh et al. [23], Alqareer et al. [24], and Farzanegan et al. [12]. The different results might be attributed to the variability in study designs and methods, patients characteristics, duration of the outcome assessment, and duration of CG.

Otasevic et al. [22] showed greater pain in the chewing group when compared chewing on bite wafers with avoidance of hard food for reduction of pain; however, bite wafer is not the same as CG. In contrast to bite wafer, which is large and affects the whole dentition when chewed on, CG is relatively soft, pliable, and represents small area which allows it to move freely around the dentition. The greater pain in the bite wafer group may be attributed to how the patients were instructed. Patients in the bite wafer group were asked to chew to avoid pain which gave the impression that the pain was inevitable, while patients in the control group were asked not to chew hard food to prevent pain giving the impression that the pain was not certain. Alqareer et al. [24] investigated the pain along a duration of 10 days after bonding the fixed orthodontic appliances and asked the patients to chew gum for a duration from 5 to 10 min which was not consistent with our study. Also, the age of the participants was different.

Al-Melh et al. [23] used a wide age range, which was different from this study, investigated the pain along a duration of $8 \mathrm{~h}$ which was very short, and asked the patients to chew gum every 25 min without specifying the duration of chewing. Farzanegan et al. [12] assessed pain experienced with the placement of fixed orthodontic appliance during biting, chewing, fitting front teeth, and fitting back teeth in patients with age range that was different as compared to this RCT and asked the patients to chew gum for $5 \mathrm{~min}$. In addition, they included only 10 patients in each group which might have affected the power to detect the difference between the included groups.

In this RCT, we assessed the pain along a duration of 1 week according to some reports [12], [25], which demonstrated that this duration was enough for the pain to diminish. However, the week duration was not compatible with Alqareer et al. [24] and Al-Melh et al. [23] who investigated the effect on pain for 10 days and $8 \mathrm{~h}$, respectively. On the other hand, the week duration was consistent with Farzanegan et al. [12], Benson et al. [19], Delavarian et al. [20], and Elvina et al. [21].
The duration of CG may have an impact on pain perception. It was reported in one study [26] that longer duration of CG might have greater effect on pain. In this $\mathrm{RCT}$, we chose 10 min duration of chewing haphazardly. The duration of CG in our study was consistent with Delavarian et al. [20] and Elvina et al. [21], but not consistent with Alqareer et al. [24], Farzanegan et al. [12], Benson et al. [19], and Al-Melh et al. [23]. Further research should be done to determine the optimal duration of $C G$ to reduce the orthodontic pain.

The pain intensity in this study reached its peak at bedtime in the NG group and after $24 \mathrm{~h}$ in the CG group. This result agreed with Farzanegan et al. [12], Elvina et al. [21], and Delavarian et al. [20], but disagreed with Alqareer et al. [24] who showed great individual variability with regards to the peak pf pain intensity.

It is well known that analgesics have an effect on pain [9], [27], [28]; hence, the patients were asked to avoid the use of any type of analgesics and to report if they used them. The degree to which the use of analgesics was controlled showed variations with regards to other studies [12], [19], [22].

The evidence regarding the effect of gender on pain is not conclusive. Some reports demonstrated that gender had no significant effect on the impact of fixed appliances [7], [29]. Another report showed that girls exhibited higher impacts than boys [30], [31] although gender was not a significant predictor of VAS values [30]. Although our study was not designed to investigate the difference between genders [32], [33], if females were to show higher pain scores than males, then the increased number of females in the CG group would have reduced the difference between the NG and $C G$ groups and reduced the possibility to find a significant difference. Consequently, the true difference between the two groups might be in fact greater.

The available reports regarding the effect of age on pain sensation are conflicting. Some reports suggested that adult experienced more pain than adolescents, although others suggested the opposite [3], 34], [35], [36]. As an attempt to rule out the effect of age as a cofounder, we were very careful not to include very young children and adults in this study; in addition, we included patients with narrow age range between 20 and 24 years.

One of the limitations of this study was the difficulty to evaluate the compliance of the patients to the given instructions regarding the duration and time of CG and not taking analgesics. Another limitation was the relatively small sample size and some patients had to be excluded as they did not follow the instructions. Including both males and females in the study could have affected the results in this RCT; therefore, future research should be directed to include one gender only to rule out the effect of gender. Despite the limitation of the inability to blind the patients and the operator 
because of the nature of the study, the outcome assessor was blinded, and consequently, the risk of bias may be considered low. An additional limitation was the use of VAS scoring which is highly subjective to assess the pain without using the objective methods such as gingival crevicular fluid pain mediators. Although instant placement of elastomeric separators can be painful for some patients, we investigated the pain after $2 \mathrm{~h}$ from separators placement.

The difference in study designs between this RCT and the studies with which our results were consistent, and the non-concordant results as compared to other studies leave the question of whether CG can reduce orthodontic pain unanswered. Therefore, future high-quality multicentric research with larger sample sizes and standardization in study design, population characteristics, duration of CG, duration of the outcome assessment, and investigating the effect of CG during all stages of orthodontic treatment is required to unravel this dilemma. Among the additional benefits of CG is the increased salivary flow with its cleansing effect that may help to reduce the demineralization which can be investigated in the future research.

\section{Conclusion}

CG significantly reduced pain resulting from orthodontic elastomeric separators placement as compared to NG controls.

\section{References}

1. Kvam E, Gjerdet NR, Bondevik O. Traumatic ulcers and pain during orthodontic treatment. Community Dent Oral Epidemiol. 1987;15(2):104-7. https://doi.org/10.1111/j.1600-0528.1987. tb00493.x

PMid:3471374

2. Lew KK. Attitudes and perceptions of adults towards orthodontic treatment in an Asian community. Community Dent Oral Epidemiol. 1993;21(1):31-5. https://doi. org/10.1111/j.1600-0528.1993.tb00715.x PMid:8432102

3. Scheurer PA, Firestone AR, Bürgin WB. Perception of pain as a result of orthodontic treatment with fixed appliances. Eur J Orthod. 1996;18(4):349-57. https://doi.org/10.1093/ejo/18.1.349 PMid:8921656

4. Polat Ö. Pain and discomfort after orthodontic appointments. Semin Orthod. 2007;13(4):292-300.

5. Krishnan V. Orthodontic pain: From causes to management-a review. Eur J Orthod. 2007;29(2):170-9. PMid:17488999

6. Nalbantgil D, Cakan DG, Oztoprak MO, Arun T. Perception of pain and discomfort during tooth separation. Aust Orthod J. 2009;25(2):110-5.

\section{PMid:20043544}

7. Bernabé E, Sheiham A, de Oliveira CM. Impacts on daily performances related to wearing orthodontic appliances. Angle Orthod. 2008;78(3):482-6. https://doi.org/10.2319/050207-212.1 PMid: 18416624

8. Al Shayea El. Comparative assessment between ibuprofen, chewing gum, and bite wafers in pain control following first archwire placement in orthodontic patients. The J Contemp Dent Pract. 2020;21(4):416-20. https://doi.org/10.5005/ jp-journals-10024-2804

PMid:32584279

9. Bradley RL, Ellis PE, Thomas P, Bellis H, Ireland AJ, Sandy JR. A randomized clinical trial comparing the efficacy of ibuprofen and paracetamol in the control of orthodontic pain. Am J Orthod Dentofacial Orthop. 2007;132(4):511-7. https://doi. org/10.1016/j.ajodo.2006.12.009 PMid:17920505

10. Ecklund CR, Ross MC. Over-the-counter medication use in preschool children. J Pediatr Health Care. 2001;15(4):168-72. https://doi.org/10.1067/mph.2001.110913

PMid:11462123

11. Proffit WR, Fields HW. Biologic basis of orthodontic therapy In: Proffit WR, Fields HW, editors. Contemporary Orthodontics. $3^{\text {rd }}$ ed. St Louis: Mosby; 2000.

12. Farzanegan F, Zebarjad SM, Alizadeh S, Ahrari F. Pain reduction after initial archwire placement in orthodontic patients: A randomized clinical trial. Am J Orthod Dentofacial Orthop. 2012;141(2):169-73. https://doi.org/10.1016/j. ajodo.2011.06.042

13. Bagnoli F, Rossetti A, Messina G, Mori A, Casucci M, Tomasini B Treatment of patent ductus arteriosus (PDA) using ibuprofen: Renal side-effects in VLBW and ELBW newborns. J Matern Fetal Neonatal Med. 2013;26(4):423-9. https://doi.org/10.3109 /14767058.2012.733775 PMid:23057804

14. Isotupa KP, Gunn S, Chen CY, Lopatin D, Mäkinen KK. Effect of polyol gums on dental plaque in orthodontic patients. Am J Orthod Dentofacial Orthop. 1995;107(5):497-504. https://doi. org/10.1016/s0889-5406(95)70117-6 PMid:7733059

15. Proffit WR, Fields HW, Sarver DM. Contemporary Orthodontics. St Louis: Mosby Elsevier; 2007.

16. Waheed-Ul-Hamid M, Haq A, Mahmood HS, Azeem M, Irfan S. Comparison between ibuprofen and chewing gum for orthodontic pain control. Pak Oral Dent J. 2016;36(1):79-83.

17. Furstman L, Bernick S. Clinical considerations of the periodontium. Am J Orthod. 1972;61(2):138-55. PMid:4500502

18. Burt BA. The use of sorbitol-and xylitol-sweetened chewing gum in caries control. J Am Dent Assoc. 2006;137(2):190-6. https:// doi.org/10.14219/jada.archive.2006.0144

PMid:16521385

19. Benson PE, Razi RM, Al-Bloushi RJ. The effect of chewing gum on the impact, pain and breakages associated with fixed orthodontic appliances: A randomized clinical trial. Orthod Craniofac Res. 2012;15(3):178-87. https://doi. org/10.1111/j.1601-6343.2012.01546.x PMid:22812440

20. Delavarian M, Imani MM, Delavarian F, Bayani S. Comparison of chewing gum and ibuprofen in alleviating orthodontic pain: A single centre, randomised clinical trial. Aust Orthod J. 2020;36(1):38-44.

21. Elvina E, Kusnoto J, Halim H, Roeslan B. Chewing gum, acetaminophen, and green tea effect in reducing pain after orthodontic appliance placement. Sci Dent J. 2018;2:51-7. 
https://doi.org/10.26912/sdj.v2i2.2530

22. Otasevic M, Naini FB, Gill DS, Lee RT. Prospective randomized clinical trial comparing the effects of a masticatory bite wafer and avoidance of hard food on pain associated with initial orthodontic tooth movement. Am J Orthod Dentofacial Orthop. 2006;130(1):6. e9-15. https://doi.org/10.1016/j.ajodo.2005.11.033

PMid:16849064

23. Al-Melh MA, Nada A, Badr $H$, Andersson L. Effect of an anesthetic chewing gum on the initial pain or discomfort from orthodontic elastomeric separator placement. J Contemp Dent Pract. 2019;20(11):1286-92. https://doi.org/10.5005/ jp-journals-10024-2708

PMid:31892680

24. Alqareer A, Alyahya A, Al-Anezi SA, AlAwadhi A, Al Qabandi S, Alyaseen M. Efficacy of chewing gum to reduce orthodontic pain compared to placebo: A blinded, parallel-group, preliminary clinical trial. J Oral Facial Pain Headache. 2019;33(3):301-7. https://doi.org/10.11607/ofph.2192

PMid:30978268

25. Lim HM, Lew KK, Tay DK. A clinical investigation of the efficacy of low level laser therapy in reducing orthodontic postadjustment pain. Am J Orthod Dentofacial Orthop. 1995;108(6):614-22. https://doi.org/10.1016/s0889-5406(95)70007-2 PMid:7503039

26. Kamiya K, Fumoto M, Kikuchi H, Sekiyama T, Mohri-Lkuzawa $Y$, Umino M, et al. Prolonged gum chewing evokes activation of the ventral part of prefrontal cortex and suppression of nociceptive responses: Involvement of the serotonergic system. J Med Dent Sci. 2010;57(1):35-43. https://doi.org/10.1016/s1090-3801(09)60930-7 PMid:20437764

27. Kohli SS, Kohli VS. Effectiveness of piroxicam and ibuprofen premedication on orthodontic patients' pain experiences. Angle Orthod. 2011;81(6):1097-102. https://doi. org/10.2319/022411-134.1 PMid:21644837

28. Polat O, Karaman Al, Durmus E. Effects of preoperative ibuprofen and naproxen sodium on orthodontic pain. Angle
Orthod. 2005;75(5):791-6.

PMid: 16279825

29. Mandall NA, Vine S, Hulland R, Worthington HV. The impact of fixed orthodontic appliances on daily life. Community Dent Health. 2006;23(2):69-74

PMid: 16800360

30. Miller KB, McGorray SP, Womack R, Quintero JC, Perelmuter M, Gibson J, et al. A comparison of treatment impacts between invisalign aligner and fixed appliance therapy during the first week of treatment. Am J Orthod Dentofacial Orthop. 2007;131(3):302. e1-9. https://doi.org/10.1016/j.ajodo.2006.05.031 PMid: 17346581

31. Wiesenfeld-Hallin Z. Sex differences in pain perception. Gend Med. 2005;2(3):137-45.

PMid:16290886

32. Bergius $M$, Berggren $U$, Kiliaridis $S$. Experience of pain during an orthodontic procedure. Eur J Oral Sci 2002;110:92-8. http:// dx.doi.org/10.1034/j.1600-0722.2002.11193.x PMid:12013568

33. Bergius M, Broberg AG, Hakeberg M, Berggren U. Prediction of prolonged pain experiences during orthodontic treatment. Am J Orthod Dentofacial Orthop 2008;133:339.e1-9.

34. Brown DF, Moerenhout RG. The pain experience and psychological adjustment to orthodontic treatment of preadolescents, adolescents, and adults. Am J Orthod Dentofacial Orthop. 1991;100(4):349-56. https://doi. org/10.1016/0889-5406(91)70073-6

PMid:1927986

35. Jones ML. An investigation into the initial discomfort caused by placement of an archwire. Eur J Orthod. 1984;6(1):48-54 PMid:6583064

36. Fernandes LM, Ogaard B, Skoglund L. Pain and discomfort experienced after placement of a conventional or a superelastic $\mathrm{NiTi}$ aligning archwire. A randomized clinical trial. J Orofac Orthop. 1998;59(6):331-9. https://doi.org/10.1007/bf01299769 PMid:9857602 